\title{
Investigation of the Diagnostic Value of Neutrophil to Lymphocyte Ratio in Pediatric Appendicitis Cases
}

\author{
Banu Karakus Yilmaz, ${ }^{1,}$ and Yahya Ayhan ACAR ${ }^{2}$ \\ ${ }^{1}$ Department of Emergency Medicine, Sisli Hamidiye Etfal Training and Research Hospital, Istanbul, Turkey \\ ${ }^{2}$ Department of Emergency Medicine, Gulhane Training and Research Hospital, Ankara, Turkey \\ "Corresponding author: Dr Banu Karakus Yilmaz, Department of Emergency Medicine, Sisli Hamidiye Etfal Training and Research Hospital, Sisli Hamidiye Etfal EAH, 19 mayıs \\ Mah. Sisli Etfal Sok, Sisli, Istanbul, Turkey. E-mail: banukarakus@yahoo.com
}

Received 2016 November 03; Revised 2016 December 27; Accepted 2017 January 29.

\begin{abstract}
Background: Abdominal pain is one of the most common complaints and appendicitis is the most common etiology of acute abdominal pain in the emergency departments for pediatric population.

Objectives: The current study aimed at evaluating the diagnostic reliability of neutrophil to lymphocyte ratio in the appendicitis in pediatric population.

Methods: The current retrospective descriptive study screened pediatric patients ( $<18$ years old) with appendectomy from January 1, 2012 to December 31, 2013 in a tertiary care setting. Data were collected via electronic hospital databases. Histopathological reports were used as the gold standard of the diagnosis and patients were divided into 2 groups of acute appendicitis (AA) and nonappendicitis (NA), according to pathologic reports. Neutrophil to lymphocyte ratio was calculated by the initial laboratory results of the patients. Statistical analysis was performed by Statistical Package for the Social Sciences (SPSS) version 15.0 (SPSS Inc., Chicago, IL).

Results: A total of 658 subjects were included in the study and 628 of them were in the AA group. There was no difference in age and gender between the 2 groups ( $P$ values $=0.872$ and 0.182 , respectively). White blood cell $(W B C)$ count $(P=0.012)$, neutrophil count $(P$ $<0.001)$, lymphocyte count $(\mathrm{P}<0.001)$, and neutrophil-to-lymphocyte ratio (NLR) $(\mathrm{P}=0.008)$ were different between the 2 groups. The results of area under the curve (AUC), according to receiver operating characteristics (ROC) analysis, were as follows: 0.669 for white blood cell count, 0.675 for neutrophil count, 0.300 for lymphocyte count, and 0.694 for neutrophil-to-lymphocyte ratio. With a cutoff value of 3.5 , sensitivity and specificity were $84.2 \%$ and $56.7 \%$, respectively.

Conclusions: Neutrophil-to-lymphocyte ratio seems a good predictor in the diagnosis of acute appendicitis in pediatric population.
\end{abstract}

Keywords: Appendicitis, Neutrophils, Lymphocytes, Pediatrics

\section{Background}

For pediatric population, abdominal pain is a common complaint in the emergency department (ED) (1). Abdominal pain was reported up to $6.2 \%$ of all pediatric emergency admissions (2). The most common etiology of acute abdominal pain in pediatric patients is acute appendicitis (3).

Diagnosis of the appendicitis is still controversial, and unfortunately clinicians have problems to arrive at a definitive diagnosis in adult and pediatric populations, even in perforated appendicitis (4). History and physical examination are still in the first line, but laboratory tests and imaging modalities are of great importance (5), because especially younger children have limitations in expressing themselves. Complete blood count (CBC) is in the first line of laboratory evaluation to diagnose appendicitis $(6,7)$. White blood cell count (WBC) is studied well in the literature, but recently, there are several CBC parameters such as red blood cell distribution width (RDW), mean platelet volume (MPV), and platelet distribu- tion width (PDW) associated with the diagnosis of appendicitis (8-11). In recent studies, neutrophil-to-lymphocyte ratio (NLR) is reported associated with several surgical clinical conditions as appendicitis, acute mesenteric ischemia, and strangulated inguinal hernia (12-14).

\section{Objectives}

The current study aimed at evaluating the diagnostic value of NLP to diagnose acute appendicitis in the pediatric patients with abdominal pain.

\section{Methods}

The current retrospective, descriptive study was approved by local ethical committee and all procedures were performed according to Helsinki declaration. Hosting hospital was a tertiary health care setting with annual pediatric emergency visit of 150,000 cases. All data were collected retrospectively from the hospital database records. 
Patients under 18 years old undergone appendectomy from January 1, 2012 to December 31, 2013 were screened for eligibility. Descriptive data including age, gender, and hospitalization time were recorded. Initial white blood cell count (WBC), hemoglobin (Hgb), hematocrit(Hct), platelet count (Plt), neutrophil count, and lymphocyte count were recorded as complete blood count (CBC) parameters at presentation. C-reactive protein (CRP) and fibrinogen were recorded as other acute inflammatory markers. As the gold standard of the diagnosis, histopathologic examination reports were recorded and accordingly, patients were divided into acute appendicitis (AA) and non-appendicitis (NA) groups.

All patients with sufficient data were included in the study. Exclusion criteria were age $\geq 18$ years, abdominal trauma, lack of enough data, having additional diseases affecting hematologic system (including lymphoma, leukemia, and bone marrow malignancies), or other chronic inflammatory diseases (including tuberculosis, Henoch-Schönlein purpura), and any autoimmune disorders.

CBC was performed with ABX Pentra XL 80 hematology analyzer (Horiba Instruments Inc., California, USA) as a routine process in the hosting facility. But, NLR was calculated for each subject via dividing neutrophil count to lymphocyte count.

\subsection{Statistical Analysis}

Frequency was used to present descriptive statistics for categorical variables. Mean \pm standard deviation (SD) was used to express continuous data with normal distribution. Primary and secondary data were compared by Chi-square test and the Student $\mathrm{t}$ test in the acute appendicitis and non-appendicitis groups. To assess the diagnostic utility of the studied parameters on acute appendicitis, receiver operating characteristic (ROC) curve analysis was performed. Statistical Package for the Social Sciences (SPSS) version 15.0 (SPSS Inc., Chicago, IL) was employed for statistical analyses, and a $\mathrm{P}<0.05$ was considered as statistically significant.

\section{Results}

During the study period, a total of 658 patients met the inclusion criteria. In the AA group, there were 628 patients with a mean age of $11.35 \pm 3.68$ years; in the NA group, there were 30 patients with a mean age of $11.23 \pm 4.64$ years. There was no difference between the 2 groups regarding age, gender, and hospitalization time $(\mathrm{P}=0.872,0.182$, and 0.713 , respectively).

WBC was elevated in both groups, but it was higher in the AA group $\left(15.94 \pm 7.07 \times 10^{3} / \mathrm{mm}^{3}\right)$ than the NA group $\left(12.66 \pm 4.81 \times 10^{3} / \mathrm{mm}^{3}\right)(\mathrm{P}=0.012)$. Lymphocyte counts were significantly lower and neutrophil counts significantly higher in the AA group than the NA group $(\mathrm{P}<$ 0.001 for both). NLR was also significantly higher in the AA group than the NA group $(\mathrm{P}=0.008)$. Hgb, Htc, RDW, MPV, platelets count, fibrinogen, and CRP levels did not show any difference between the 2 groups $(\mathrm{P}=0.248,0.420$, $0.929,0.498,0.148,0.253$, and 0.227 , respectively) (Table 1).

ROC curves are given in Figure 1, and AUC values for WBC, neutrophil ratio, lymphocyte ratio, and NLR were $0.669,0.675,0.300$, and 0.694 , respectively. According to ROC curves, cutoff value of NLR was 3.5. Sensitivity, specificity, positive likelihood ratio, negative likelihood ratio, positive predictive value, and negative predictive value were $84.2 \%, 56.7 \%, 1.94,0.28,97.6 \%$, and $14.7 \%$, respectively according to a cutoff value of 3.5 for NLR.

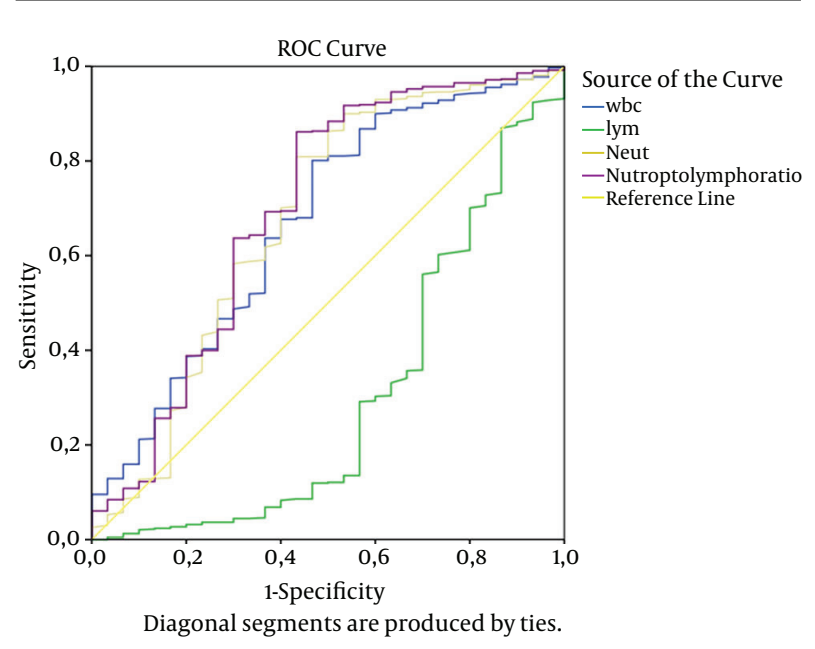

Figure 1. ROC Curves

\section{Discussion}

The result of the current study indicated that higher NLR levels may be a good marker in the diagnosis of acute appendicitis in pediatric population. Although WBC, neutrophil count, and lymphocyte count seem beneficial as a calculated value, NLR increased the individual diagnostic significance of the neutrophil and lymphocyte counts.

In a retrospective study, Kucuk et al. reported that NLR could be useful to diagnose adult patients with acute appendicitis. Their data suggested that the cutoff value of NLR was 1.71:1 to diagnose acute appendicitis with a sensitivity of $97 \%$ and specificity of $87 \%$ (15). Their data also suggested that NLR increased the AUC values compared to individual neutrophil count and lymphocyte count. Markar 
Table 1. Comparison of the Acute Appendicitis and Non-Appendicitis Groups ${ }^{\mathrm{a}}$

\begin{tabular}{|c|c|c|c|}
\hline Variables & Non-appendicitis Group $(\mathbf{n}=\mathbf{3 0})$ & Appendicitis Group $(n=628)$ & P Value \\
\hline Age & $11.23 \pm 4.64(-1.48-1.25)$ & $11.35 \pm 3.68(-1.87-1.64)$ & $0.872^{\mathrm{b}}$ \\
\hline Gender (female/male) & $13 / 17$ & $199 / 429$ & $.182^{\mathrm{C}}$ \\
\hline Hospitalization time, day & $3.97 \pm 2.29(-0.89-1.31)$ & $3.76 \pm 2.99(-0.69-1.11)$ & $0.713^{\mathrm{b}}$ \\
\hline $\mathrm{WBC}, \times 10^{3} / \mathrm{mm}^{3}$ & $12.66 \pm 4.81(-5.85--0.72)$ & $15.94 \pm 7.07(-5.15--1.41)$ & $0.012^{\mathrm{b}}$ \\
\hline Lymphocyte, \% & $24.72 \pm 22.68(8.34-16.08)$ & $12.51 \pm 9.61(3.71-120.71)$ & $<0.001^{\mathrm{b}}$ \\
\hline Neutrophil, \% & $70.28 \pm 16.51(-14.09--4.77)$ & $79.71 \pm 12.51(-15.66--3.20)$ & $<0.001^{\mathrm{b}}$ \\
\hline NLR & $6.48 \pm 6.58(-6.40--0.97)$ & $10.16 \pm 7.44(-6.20--1.16)$ & $0.008^{\mathrm{b}}$ \\
\hline Hemoglobin, mg/dL & $12.69 \pm 1.32(-0.82-0.21)$ & $12.99 \pm 1.41(-0.81-0.19)$ & $0.248^{\mathrm{b}}$ \\
\hline Hematocrit, \% & $4.08 \pm 0.75(-2.32-0.97)$ & $4.50 \pm 0.18(-2.24-0.89)$ & $0.420^{\mathrm{b}}$ \\
\hline RDW, \% & $13.92 \pm 1.34(-0.36-0.39)$ & $13.91 \pm 1.02(-0.49-0.52)$ & $0.929^{\mathrm{b}}$ \\
\hline MPV, fL & $7.51 \pm 0.95(-0.46-0.22)$ & $7.63 \pm 0.92(-0.48-0.25)$ & $0.498^{\mathrm{b}}$ \\
\hline Platelet, $\times 10^{3} / \mathrm{uL}$ & $325.83 \pm 118.44(-8.65-57.43)$ & $301.44 \pm 88.51(-20.32-69.10)$ & $0.148^{\mathrm{b}}$ \\
\hline Fibrinogen, $\mathrm{mg} / \mathrm{dL}$ & $123.41 \pm 156.87(-256.40-67.73)$ & $217.75 \pm 215.61(-239.80-51.14)$ & $0.253^{\mathrm{b}}$ \\
\hline CRP, mg/dL & $150.98 \pm 567.97(-2023.84-482.05)$ & $921.87 \pm 3184.71(-1121.15--420.63)$ & $0.227^{\mathrm{b}}$ \\
\hline
\end{tabular}

Abbreviations: CI, Confidence Interval; CRP, C-Reactive Protein; MPV, Mean Platelet Volume; NLR, Neutrophil-to-Lymphocyte Ratio; RDW, Red Cell Distribution Width; SD Standard Deviation; WBC, White Blood Cell Count.

${ }^{\mathrm{a}}$ Value are expressed as Mean $\pm \mathrm{SD}$, (95\% CI).

${ }^{\mathrm{b}}$ The Student $\mathrm{t}$ test for independent samples.

chi-square test.

et al., reported similar data in their study on adult patients with appendectomy. Their cutoff value for NLR was 6.0 with a sensitivity and specificity of $71 \%$ and $80 \%$, respectively (16); and their data were compatible with those of the current study supposing the increased diagnostic accuracy of NLR compared to its determinants.

Besides the diagnosis, NLR was reported valuable to predict severity of the AA. Yardimci et al., found that NLR levels were higher in patients with complicated appendicitis in adult population. With a cutoff value of 7.95, NLR was detected in the cases with complicated appendicitis, with a sensitivity and specificity of $78 \%$ and $67 \%$, respectively (17). Kahramanca et al., reported the cutoff value of NLR to diagnose the AA as 4.68, but in the same study, as a subgroup analysis, NLR showed a good performance to differentiate between complicated and non-complicated appendicitis with a cutoff value of 9.85, supposing that the higher NLR, the higher complication rates (18). Timing of appendectomy is sometimes controversial, especially in pediatric patients. Although there are no data on pediatric patients, NLR can be useful to monitor the subjects with acute appendicitis.

In their retrospective cohort study, Kelly et al. compared the adult and pediatric patients who underwent emergent appendectomy. According to their data, NLR was a good indicator to predict severity of appendicitis and es- timate the length of the stay time; cutoff value was higher in the pediatric population (7.53, sensitivity: $80 \%$, specificity: 55\%) compared with that of the adults (6.35, sensitivity: 85\%, specificity: 48\%) (19). The current study did not evaluate the severity of appendicitis, but there was no difference in the length of stay between the AA and NA groups.

Yazici et al., retrospectively evaluated pediatric patients who underwent appendectomy and compared different cutoff values for NLR. According to their data, a cutoff value of 3.5 seems valuable (sensitivity: 90\%, specificity: $88 \%$ ) to diagnose AA in pediatric patients (20). Their results were consistent with the current study data, supporting the reliability of NLR to diagnose acute appendicitis.

Not only diagnosis, but also exclusion is important. Wang et al., reported that absence of the left shift had a negative predictive value of $90 \%$ to exclude appendicitis in the pediatric patients with non-traumatic abdominal pain (21). The current study data showed a negative predictive value of $14.7 \%$ in the pediatric population with appendicitis. However these 2 studies had distinct results; Wang et al., assessed left shift as a categorical (yes/no) value, but the current study results were based on continuous data.

NLR was reported valuable in the outcome prediction of postoperative phase in the elderly with a higher cutoff value (22.85) than adult and pediatric populations. But, with this cutoff point, NLR was reported as an independent 
factor in the 30-day postoperative mortality estimation of the elderly (22). The current study did not have a follow-up period and therefore, it could not assess the mortality or outcomes.

\subsection{Limitations}

It was a retrospective study and randomization was not performed. Complications were not recorded specifically. There was a limited number of subjects in the control group.

\subsection{Conclusion}

The current study demonstrated that NLR seems a valuable marker to diagnose acute appendicitis in the pediatric population. Despite the high-tech modalities, as a simple test, CBC is still of great importance to evaluate abdominal pain. Physicians should assess as many different clues as possible, and NLR seems to become increasingly important.

\section{Acknowledgments}

The authors sincerely thank Hatice Topcu MD for data collection and Erdem Cevik MD for statistical analysis.

\section{References}

1. Olympia RP, Wilkinson R, Dunnick J, Dougherty BJ, Zauner D. Pediatric Referrals to an Emergency Department From Urgent Care Centers. Pediatr Emerg Care. 2016 doi: 10.1097/PEC.0000000000000955. [PubMed: 27753717].

2. Caperell K, Pitetti R, Cross KP. Race and acute abdominal pain in a pediatric emergency department. Pediatrics. 2013;131(6):1098-106. doi: 10.1542/peds.2012-3672. [PubMed: 23690514].

3. Tseng YC, Lee MS, Chang YJ, Wu HP. Acute abdomen in pediatric patients admitted to the pediatric emergency department. Pediatr Neonatol. 2008;49(4):126-34. doi: 10.1016/S1875-9572(08)60027-3. [PubMed: 19054918].

4. Farzal Z, Farzal Z, Khan N, Fischer A. The diagnostic dilemma of identifying perforated appendicitis. J Surg Res. 2015;199(1):164-8. doi: 10.1016/j.jss.2015.04.058. [PubMed: 25976856].

5. Hansen LW, Dolgin SE. Trends in the Diagnosis and Management of Pediatric Appendicitis. Pediatr Rev. 2016;37(2):52-7. doi:10.1542/pir.20150021. [PubMed: 26834224] quiz 58.

6. Khanafer I, Martin DA, Mitra TP, Eccles R, Brindle ME, Nettel-Aguirre A, et al. Test characteristics of common appendicitis scores with and without laboratory investigations: a prospective observational study. BMC Pediatr. 2016;16(1):147. doi: 10.1186/s12887-016-0687-6. [PubMed: 27577252].

7. Benito J, Acedo Y, Medrano L, Barcena E, Garay RP, Arri EA. Usefulness of new and traditional serum biomarkers in children with suspected appendicitis. Am J Emerg Med. 2016;34(5):871-6. doi: 10.1016/j.ajem.2016.02.011. [PubMed: 26935221].
8. Bozlu G, Taskinlar H, Unal S, Alakaya M, Nayci A, Kuyucu N. Diagnostic value of red blood cell distribution width in pediatric acute appendicitis. Pediatr Int. 2016;58(3):202-5. doi: 10.1111/ped.12805. [PubMed: 26273790].

9. Uyanik B, Kavalci C, Arslan ED, Yilmaz F, Aslan O, Dede S, et al. Role of mean platelet volume in diagnosis of childhood acute appendicitis. Emerg Med Int. 2012;2012:823095. doi: 10.1155/2012/823095. [PubMed: 22970376].

10. Bilici S, Sekmenli T, Goksu M, Melek M, Avci V. Mean platelet volume in diagnosis of acute appendicitis in children. Afr Health Sci. 2011;11(3):427-32. [PubMed: 22275934].

11. Fan Z, Pan J, Zhang Y, Wang Z, Zhu M, Yang B, et al. Mean Platelet Volume and Platelet Distribution Width as Markers in the Diagnosis of Acute Gangrenous Appendicitis. Dis Markers. 2015;2015:542013. doi: 10.1155/2015/542013. [PubMed: 26688600].

12. Zhou H, Ruan X, Shao X, Huang X, Fang G, Zheng X. Clinical value of the neutrophil/lymphocyte ratio in diagnosing adult strangulated inguinal hernia. Int J Surg. 2016;36(Pt A):76-80. doi: 10.1016/j.ijsu.2016.10.026. [PubMed: 27771521].

13. Cigsar G, Yildirim AC, Anuk T, Guzel H, Gunal E, Gulkan S, et al Neutrophil to Lymphocyte Ratio on Appendectomy of Geriatric and Nongeriatric Patients. J Invest Surg. 2016:1-6. doi: 10.1080/08941939.2016.1241324. [PubMed: 27780371].

14. Aktimur R, Cetinkunar S, Yildirim K, Aktimur SH, Ugurlucan M, Ozlem N. Neutrophil-to-lymphocyte ratio as a diagnostic biomarker for the diagnosis of acute mesenteric ischemia. Eur J Trauma Emerg Surg. 2016;42(3):363-8. doi: 10.1007/s00068-015-0546-4. [PubMed: 26059561].

15. Kucuk E. The change of neutrophil lymphocyte ratio in acute appendicitis. Med Sci. 2015;4(3):2379-87. doi: 10.5455/medscience.2015.04.8265.

16. Markar SR, Karthikesalingam A, Falzon A, Kan Y. The diagnostic value of neutrophil: lymphocyte ratio in adults with suspected acute appendicitis. Acta Chir Belg. 2010;110(5):543-7. [PubMed: 21158332].

17. Yardimci S, Ugurlu MU, Coskun M, Attaallah W, Yegen SC. Neutrophillymphocyte ratio and mean platelet volume can be a predictor for severity of acute appendicitis. Ulus Travma Acil Cerrahi Derg. 2016;22(2):163-8. doi: 10.5505/tjtes.2015.89346. [PubMed: 27193984].

18. Kahramanca S, Ozgehan G, Seker D, Gokce EI, Seker G, Tunc G, et al. Neutrophil-to-lymphocyte ratio as a predictor of acute appendicitis. Ulus Travma Acil Cerrahi Derg. 2014;20(1):19-22. doi: 10.5505/tjtes.2014.20688. [PubMed: 24639310].

19. Kelly ME, Khan A, Riaz M, Bolger JC, Bennani F, Khan W, et al. The Utility of Neutrophil-to-Lymphocyte Ratio as a Severity Predictor of Acute Appendicitis, Length of Hospital Stay and Postoperative Complication Rates. Dig Surg. 2015;32(6):459-63. doi: 10.1159/000440818. [PubMed: 26488396].

20. Yazici M, Ozkisacik S, Oztan MO, Gursoy H. Neutrophil/lymphocyte ratio in the diagnosis of childhood appendicitis. Turk I Pediatr 2010;52(4):400-3. [PubMed: 21043386].

21. Wang LT, Prentiss KA, Simon JZ, Doody DP, Ryan DP. The use of white blood cell count and left shift in the diagnosis of appendicitis in children. Pediatr Emerg Care. 2007;23(2):69-76. doi: 10.1097/PEC.ob013e31802d1716. [PubMed: 17351404].

22. Vaughan-Shaw PG, Rees JR, King AT. Neutrophil lymphocyte ratio in outcome prediction after emergency abdominal surgery in the elderly. Int J Surg. 2012;10(3):157-62. doi: 10.1016/j.ijsu.2012.02.010. [PubMed: 22361307]. 